\title{
COMPARISON OF BILIARY LEAKAGE IN LAPAROSCOPIC AND OPEN CHOLECYSTECTOMY
}

Shadab Asif1, Satendra Pratap Singh Yadav², Saleem Tahir ${ }^{3}$, Ateev Ashok Singh4, Saurabh Rai ${ }^{5}$, Saurabh Singh ${ }^{6}$, Anurag Singh ${ }^{7}$, Saboor Mateen ${ }^{8}$

${ }_{1}^{1}$ Assistant Professor, Department of General Surgery, Era's Lucknow Medical College and Hospital, Lucknow, Uttar Pradesh. 2Junior Resident, Department of General Surgery, Era's Lucknow Medical College and Hospital, Lucknow, Uttar Pradesh. 3 Professor, Department of General Surgery, Era's Lucknow Medical College and Hospital, Lucknow, Uttar Pradesh. 4Junior Resident, Department of General Surgery, Era's Lucknow Medical College and Hospital, Lucknow, Uttar Pradesh. 5Junior Resident, Department of General Surgery, Era's Lucknow Medical College and Hospital, Lucknow, Uttar Pradesh. 6Junior Resident, Department of General Surgery, Era's Lucknow Medical College and Hospital, Lucknow, Uttar Pradesh. 7Junior Resident, Department of General Surgery, Era's Lucknow Medical College and Hospital, Lucknow, Uttar Pradesh. 8Intern, Department of General Surgery, Era's Lucknow Medical College and Hospital, Lucknow, Uttar Pradesh.

ABSTRACT
BACKGROUND
Laparoscopic surgery is unsafe and technically impossible in case a gall-bladder disease has changed the usual anatomic
landmarks. Though, open cholecystectomy has fewer incidents of biliary leakage, the risk cannot be avoided. However, it seems
that with adoption of preventive measures and requisite skills, the biliary leakage rate has been controlled in laparoscopic surgery.
The study aimed to compare the frequency and cause of biliary leak between laparoscopic (LC) and open cholecystectomy (OC).

\section{MATERIALS AND METHODS}

A prospective observational study carried out in Department of Surgery, Era's Lucknow Medical College and Hospital, Lucknow from January 2016 to June 2017 (18 months). Out of 220 patients, 140 were subjected to LC and 80 to OC. Intra- and postoperative findings were analysed and the patients were followed up for 3 months.

\section{RESULTS}

Mean age of patients of OC (43.88 \pm 12.26 years) was higher than LC (38.93 \pm 12.37 years). Majority of patients $(75.00 \%)$ were females. Mean duration of hospital stay among patients of OC ( $3.36 \pm 2.80$ days) was higher as compared to LC ( $2.53 \pm 1.31$ days) $(p=0.009)$. All cases of biliary leak were peripheral in nature, managed conservatively and did not develop peritonitis/ sepsis. Amount of drainage in OC was higher than LC on Day 1 P.O. (45.95 \pm 16.35 vs. $27.95 \pm 14.07 \mathrm{~mL})$ and on Day 2 (26.41 \pm 13.71 vs. $17.83 \pm 11.69 \mathrm{~mL}$ ). Haematological assessment showed a generalised increase in TLC and polymorph count and low lymphocyte count. Bile leak was observed in $5(3.7 \%)$ cases of LC as compared to $2(2.5 \%)$ cases of OC.

\section{CONCLUSION}

The incidence of bile leak in both categories was comparable and in agreement with the reported literature. Although, the cause of bile leak was primarily visualisation in both the groups; however, necrosis and ischaemia were suggestive of gangrenous cholecystitis also posed risk of bile leak.

\section{KEYWORDS}

Laparoscopy, Complication, Infection, Biliary Leak.

HOW TO CITE THIS ARTICLE: Asif S, Yadav SPS, Tahir S, et al. Comparison of biliary leakage in laparoscopic and open cholecystectomy. J. Evolution Med. Dent. Sci. 2018;7(18):2274-2280, DOI: 10.14260/jemds/2018/511

\section{BACKGROUND \\ Cholecystectomy is one of the most common surgeries in the United States. ${ }^{1}$ Cholecystectomy is performed due to inflammation of gall-bladder, a condition called Cholecystitis or due to formation of gall bladder stones ${ }^{2}$ (Cholelithiasis). Laparoscopic surgery has emerged as a faster, more convenient and responsive method of surgery with lesser hospitalisation, less pain and better cosmetic appearance when compared to open surgery technique. Open surgery}

'Financial or Other Competing Interest': None.

Submission 21-03-2018, Peer Review 14-04-2018,

Acceptance 20-04-2018, Published 30-04-2018.

Corresponding Author:

Dr. Satendra Pratap Singh Yadav,

A-10, PG Boy's Hostel, Era's Lucknow Medical College

and Hospital, Sarafarazganj, Hardoi Road,

Lucknow-226003, Uttar Pradesh.

E-mail: ysatendra22@gmail.com

DOI: $10.14260 /$ jemds $/ 2018 / 511$ techniques which were prevalent earlier needed more recovery time and had higher post-operative trauma, which lead to psychological pressure on the subjects and thus decreased the efficiency of the technique, but laparoscopic cases reported complications of bile leaks (biloma) and bile duct injuries. ${ }^{3}$

Laparoscopic surgery is unsafe and technically impossible in case a gall-bladder disease has changed the usual anatomic landmarks. ${ }^{4}$ It can be said that the efficiency of the technique can be increased, and bile leaks can be avoided by experience of ERCP and laparoscopy. ${ }^{5}$ Though, open cholecystectomy has fewer incidents of biliary leakage, the risk cannot be avoided altogether.

Contrary to earlier reports showing a higher incidence of bile leak in laparoscopic cholecystectomy, some recent reports based on large clinical series present an altogether different picture.6,7 With the changing scenario, it seems that with adoption of preventive measures and acquisition of requisite skills, the biliary leakage rate has been controlled in 
laparoscopic surgery and the picture has just been reversed. However, despite these promising reports in favour of laparoscopic cholecystectomy, this controversy has still not been resolved.

\section{Aim}

To compare the frequency of biliary leak between laparoscopic and open cholecystectomy.

\section{Objectives}

1. To analyse the rate of biliary leak between laparoscopic and open cholecystectomy.

2. To determine the causes of biliary leak between laparoscopic and open cholecystectomy.

3. To study the management and outcome of biliary leak cases.

\section{MATERIALS AND METHODS}

- The present study was carried out as a prospective observational study.

- The study was carried out at Department of Surgery, Era's Lucknow Medical College, Lucknow.

- Duration of the study was eighteen months.

- A total of 220 patients were observed.

\section{Inclusion Criteria}

All patients undergoing cholecystectomy (laparoscopic and open) for cholelithiasis aged above 18 years at this hospital.

\section{Exclusion Criteria}

- Patient with cholecystectomy along with Common Bile Duct exploration.

- $\quad$ Patient with obstructive jaundice.

- All those patients in whom after cholecystectomy histopathology confirmed carcinoma.

- Laparoscopic converted open cholecystectomy.

- All those patients who underwent cholecystectomy elsewhere and came with post-operative biliary leakage.

\section{Methodology}

After obtaining an informed consent, demographic information, duration and nature of complaints were noted. Clinical examination of all the patients was done and necessary laboratory/ radiographic investigations were done before planning for surgery. Patients were enquired about the treatment of any other disease, medications and supplements being taken by the patient. Patients were stopped to take certain medications and/or supplements leading to increased risk of bleeding if needed.

All the patients were described about the two treatment modalities- laparoscopic and open and financial consequences involved, emergencies, complications and benefits. The choice of procedure was left on the patient only. On the basis of type of surgery performed, the patients were divided into following groups:

\section{Group I (Laparoscopic Cholecystectomy)}

All those patients undergoing laparoscopic cholecystectomy were placed in Group I.

\section{Group II (Open Cholecystectomy)}

All those patients undergoing open cholecystectomy were placed in Group II.

On the day of surgery, patient was transferred to Pre-Care area before 1 hour of surgery and was prepared for the operation. Patient was transferred to operating room after proper checkup. Laparoscopic or open cholecystectomy was performed as per standard protocol. Intra-operative findings were recorded on the case sheet and was analysed.

Post-operatively, drain was placed in all patients as per protocol. After surgery, patients/ attendants of patients were further instructed of do's and don'ts and were followed up for 3 months.

\section{Statistical Tools Employed}

The statistical analysis was done using SPSS (Statistical Package for Social Sciences) Version 15.0 statistical Analysis Software. The values were represented in Number (\%) and Mean \pm SD. The following Statistical formulas were usedMean, Standard Deviation, Median, Chi-Square Test, Student's ' $\mathrm{t}$ ' test.

\section{RESULTS}

Out of which, 220 cases fulfilling the inclusion criteria were included in the study. Group wise distribution of study

\begin{tabular}{|c|c|c|c|c|}
\hline $\begin{array}{c}\text { Sl. } \\
\text { No. }\end{array}$ & Group & Description & $\begin{array}{c}\text { No. of } \\
\text { Cases }\end{array}$ & $\%$ \\
\hline 1- & $\begin{array}{c}\text { Group } \\
\text { I }\end{array}$ & $\begin{array}{c}\text { Patients who had } \\
\text { undergone } \\
\text { laparoscopic } \\
\text { cholecystectomy }\end{array}$ & 140 & 63.64 \\
\hline $2-$ & $\begin{array}{c}\text { Group } \\
\text { II }\end{array}$ & $\begin{array}{c}\text { Patients who had } \\
\text { undergone open } \\
\text { cholecystectomy }\end{array}$ & 80 & 36.36 \\
\hline \multicolumn{4}{|c|}{ Table 1. Group Wise Distribution of Study Population } \\
\hline
\end{tabular}

Out of 220 cases of cholecystectomy, 140 (63.64\%) had undergone laparoscopic cholecystectomy and rest 80 $(36.36 \%)$ had undergone open cholecystectomy.

\begin{tabular}{|c|c|c|c|c|c|c|c|}
\hline \multirow{2}{*}{$\begin{array}{l}\text { Sl. } \\
\text { No. }\end{array}$} & \multirow{2}{*}{$\begin{array}{l}\text { Age } \\
\text { Group }\end{array}$} & \multicolumn{2}{|c|}{$\begin{array}{c}\text { Group I } \\
(n=140)\end{array}$} & \multicolumn{2}{|c|}{$\begin{array}{c}\text { Group II } \\
(n=80)\end{array}$} & \multicolumn{2}{|c|}{$\begin{array}{c}\text { Total } \\
(\mathrm{N}=220)\end{array}$} \\
\hline & & No. & $\%$ & No. & $\%$ & No. & $\%$ \\
\hline $1-$ & $\leq 20$ years & 3 & 2.14 & 0 & 0.00 & 3 & 1.36 \\
\hline $2-$ & $21-30$ years & 45 & 32.14 & 15 & 18.75 & 60 & 27.27 \\
\hline $3-$ & $31-40$ years & 40 & 28.57 & 16 & 20.00 & 56 & 25.45 \\
\hline 4- & $41-50$ years & 29 & 20.71 & 26 & 32.50 & 55 & 25.00 \\
\hline 5- & 51-60 years & 14 & 10.00 & 14 & 17.50 & 28 & 12.73 \\
\hline \multirow[t]{5}{*}{ 6- } & $>60$ years & 9 & 6.43 & 9 & 11.25 & 18 & 8.18 \\
\hline & & \multicolumn{4}{|c|}{$c^{2}=13.057(d f=5) ; p=0.023$} & & \\
\hline & $\begin{array}{l}\text { Min-Max } \\
\text { (Median) }\end{array}$ & \multicolumn{2}{|c|}{$19-80(38.00)$} & \multicolumn{2}{|c|}{$22-72(45.00)$} & \multicolumn{2}{|c|}{$19-80(40.00)$} \\
\hline & Mean \pm SD & \multicolumn{2}{|c|}{$38.93 \pm 12.37$} & \multicolumn{2}{|c|}{$43.88 \pm 12.26$} & \multicolumn{2}{|c|}{$40.73 \pm 12.53$} \\
\hline & & \multicolumn{4}{|c|}{$' t '=-2.863 ; p=0.005$} & & \\
\hline & & & & & & & \\
\hline
\end{tabular}

Proportion of cases of Group I was higher as compared to Group II among low age groups. Mean age of patients of Group II (43.88 \pm 12.26 years) was significantly higher as compared to Group I ( $38.93 \pm 12.37$ years). 


\begin{tabular}{|c|c|c|c|c|c|c|c|}
\hline \multirow{2}{*}{ Sl. No. } & \multirow{2}{*}{ Gender } & \multicolumn{2}{|c|}{ Group I $(n=140)$} & \multicolumn{2}{|c|}{ Group II $(n=80)$} & \multicolumn{2}{|c|}{ Total $(n=220)$} \\
\hline & & No. & $\%$ & No. & $\%$ & No. & $\%$ \\
\hline $1-$ & Female & 108 & 77.14 & 57 & 71.25 & 165 & 75.00 \\
\hline \multirow[t]{3}{*}{$2-$} & Male & 32 & 22.86 & 23 & 28.75 & 55 & 25.00 \\
\hline & Male: Female & \multicolumn{2}{|c|}{0.30} & \multicolumn{2}{|c|}{0.40} & \multicolumn{2}{|c|}{0.33} \\
\hline & & \multicolumn{4}{|c|}{$c^{2}=0.943(d f=1) ; p=0.332$} & & \\
\hline
\end{tabular}

Majority of overall patients (75.00\%) were females. Overall, Male: Female ratio was 0.33 and in Group I and Group II 0.40 and 0.30 respectively.

\begin{tabular}{|c|c|c|c|c|c|c|c|}
\hline \multirow{2}{*}{ Sl. No. } & \multirow{2}{*}{$\begin{array}{l}\text { Haematological } \\
\text { Variables }\end{array}$} & \multicolumn{2}{|c|}{ Group I $(n=140)$} & \multicolumn{2}{|c|}{ Group II $(n=80)$} & \multicolumn{2}{|c|}{ Significance of Difference } \\
\hline & & Mean & SD & Mean & SD & 't' & 'p' \\
\hline 1- & $\mathrm{Hb}(\mathrm{gm} / \mathrm{dL})$ & 12.29 & 0.74 & 12.18 & 0.83 & 1.040 & 0.300 \\
\hline $2-$ & TLC $(000)$ & 11.32 & 0.52 & 11.38 & 0.57 & -0.716 & 0.475 \\
\hline 3- & Polymorph (\%) & 81.84 & 4.75 & 82.93 & 3.76 & -1.761 & 0.080 \\
\hline 4- & Lymphocytes (\%) & 15.39 & 4.48 & 14.44 & 3.39 & 1.646 & 0.101 \\
\hline $5-$ & Eosinophils (\%) & 1.51 & 1.31 & 1.58 & 1.13 & -0.387 & 0.699 \\
\hline 6- & Monocytes (\%) & 0.86 & 0.69 & 0.96 & 0.60 & -1.083 & 0.280 \\
\hline
\end{tabular}

Haematologically, the two groups were matched and did not show any significant difference.

\begin{tabular}{|c|c|c|c|c|c|c|c|}
\hline \multirow{2}{*}{$\begin{array}{r}\text { Sl. } \\
\text { No. }\end{array}$} & \multirow{2}{*}{ Biochemical Variables } & \multicolumn{2}{|c|}{ Group I $(n=140)$} & \multicolumn{2}{|c|}{ Group II $(n=80)$} & \multicolumn{2}{|c|}{ Significance of Difference } \\
\hline & & Mean & SD & Mean & SD & 't' & 'p' \\
\hline $1-$ & RBS (mg/dL) & 133.39 & 17.74 & 135.88 & 15.48 & -1.045 & 0.297 \\
\hline $2-$ & S. Urea $(\mathrm{U} / \mathrm{mL})$ & 29.79 & 6.30 & 30.55 & 5.59 & -0.892 & 0.373 \\
\hline $3-$ & S. Creatinine $(\mathrm{U} / \mathrm{mL})$ & 1.01 & 0.21 & 1.06 & 0.22 & 1.670 & 0.096 \\
\hline $4-$ & S. $\mathrm{Na}^{+}$ & 141.01 & 2.97 & 140.60 & 3.39 & 0.929 & 0.354 \\
\hline $5-$ & S. $\mathrm{K}^{+}$ & 4.15 & 0.35 & 4.08 & 0.33 & 1.394 & 0.165 \\
\hline $6-$ & S. Bilirubin & 0.87 & 0.09 & 0.84 & 0.11 & 1.922 & 0.056 \\
\hline $7-$ & SGOT & 39.59 & 4.16 & 39.61 & 4.05 & -0.046 & 0.963 \\
\hline $8-$ & SGPT & 51.19 & 61.85 & 42.59 & 2.67 & 1.242 & 0.216 \\
\hline 9- & S. Alkaline phosphatase & 91.33 & 14.76 & 95.73 & 18.31 & -1.945 & 0.053 \\
\hline
\end{tabular}

Table 5. Between Group Comparison of Biochemical Variables

Statistically, there were no significant differences between two groups with respect to mean serum biochemical levels.

\begin{tabular}{|c|c|c|c|c|c|c|c|}
\hline \multirow{2}{*}{$\begin{array}{c}\text { Sl. } \\
\text { No. }\end{array}$} & \multirow{2}{*}{ Number of GB Stones } & \multicolumn{2}{|c|}{ Group I (n= 140) } & \multicolumn{2}{c|}{ Group II (n= 80) } & \multicolumn{2}{c|}{ Total (n= 220) } \\
\cline { 2 - 8 } & No. & \% & No. & \% & No. & \% \\
\hline $1-$ & Multiple & 84 & 60.00 & 47 & 58.75 & 131 & 59.55 \\
\hline $2-$ & Single & 56 & 40.00 & 33 & 41.25 & 89 & 40.45 \\
\hline \multicolumn{7}{|c|}{$\mathrm{c}^{2}=0.033(\mathrm{df}=1) ; \mathrm{p}=0.856$} \\
\hline
\end{tabular}

Ultrasonographically, majority of overall (59.55\%) as well as Group I (60.00\%) and Group II (58.75\%) had multiple GB stones, in rest of the patients single GB stone was found. Difference in number of GB stones among patients of Group I and Group II was not found to be statistically significant.

\begin{tabular}{|c|c|c|c|c|c|c|c|}
\hline \multirow{2}{*}{ Sl. No. } & \multirow{2}{*}{ Intra-0p Findings } & \multicolumn{2}{|c|}{ Group I (n= 140) } & \multicolumn{2}{|c|}{ Group II (n= 80) } & \multicolumn{2}{|c|}{ Total $(n=220)$} \\
\hline & & No. & $\%$ & No. & $\%$ & No. & $\%$ \\
\hline \multirow{2}{*}{$1-$} & GB Wall Oedema & 20 & 14.29 & 8 & 10.00 & 28 & 12.73 \\
\hline & \multicolumn{5}{|c|}{$c^{2}=0.842(d f=1) ; p=0.359$} & & \\
\hline \multirow{4}{*}{$2-$} & \multicolumn{7}{|c|}{ Adhesions } \\
\hline & Absent & 107 & 76.43 & 62 & 77.50 & 169 & 76.82 \\
\hline & Present & 33 & 23.57 & 18 & 22.50 & 51 & 23.18 \\
\hline & \multicolumn{5}{|c|}{$c^{2}=0.033(d f=1) ; p=0.856$} & & \\
\hline \multirow{4}{*}{$3-$} & \multicolumn{7}{|c|}{ Identification of Calot's triangle } \\
\hline & Easy & 127 & 90.71 & 72 & 90.00 & 199 & 90.45 \\
\hline & Difficult & 13 & 9.29 & 8 & 10.00 & 21 & 9.55 \\
\hline & & \multicolumn{4}{|c|}{$c^{2}=0.030(d f=1) ; p=0.850$} & & \\
\hline
\end{tabular}




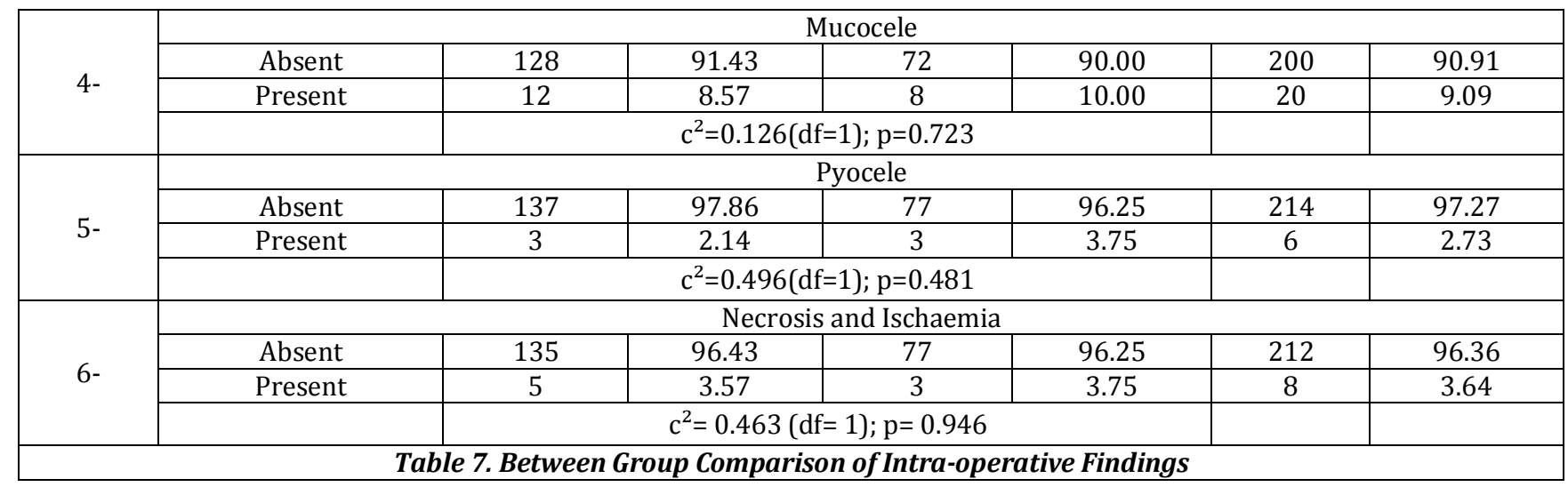

Intra-operatively oedema was found to be present on GB wall of all the patients. Adhesions were found in higher proportion of patients of Group I (23.57\%) as compared to Group II $(22.50 \%)$. Difficulty in identification of Calot's triangle was observed in higher proportion of patients of Group II (10.00\%) as compared to Group I (9.29\%). Mucocele was found among higher proportion of patients of Group II (10.00\%) as compared to Group I (8.57\%). Pyocele was found among higher proportion of patients of Group II (3.75\%) as compared to Group I (2.14\%). Necrosis and ischaemia suggestive of gangrenous cholecystitis was seen in $5(3.57 \%)$ of Group I and 3 (3.75\%) of Group II cases. Statistically, there was no significant difference between two groups in these findings.

\begin{tabular}{|c|c|c|c|c|c|}
\hline Group & No. & Min. & Max. & Mean & S.D. \\
\hline Group I & 140 & 1 & 12 & 2.53 & 1.31 \\
\hline $\begin{array}{c}\text { Group } \\
\text { II }\end{array}$ & 80 & 2 & 20 & 3.26 & 2.80 \\
\hline Total & $\mathbf{2 2 0}$ & $\mathbf{1}$ & $\mathbf{2 0}$ & $\mathbf{2 . 8 0}$ & $\mathbf{2 . 0 2}$ \\
\hline \multicolumn{6}{|c|}{ Table 8. Between Group Comparison of Hospital } \\
Stay (' $\boldsymbol{t}$ '= 2.626, $\mathbf{p = 0 . 0 0 9 )}$
\end{tabular}

Duration of hospital stay ranged between 1 - 27 days. Mean duration of hospital stay among patients of Group II (3.36 \pm 2.80 days) was significantly higher as compared to Group I ( $2.53 \pm 1.31$ days) ( $\mathrm{p}=0.009$ ).

\begin{tabular}{|c|c|c|c|c|c|c|c|}
\hline \multirow{2}{*}{$\begin{array}{l}\text { Sl. } \\
\text { No. }\end{array}$} & \multirow{2}{*}{$\begin{array}{c}\text { Bile } \\
\text { Leak }\end{array}$} & \multicolumn{2}{|c|}{$\begin{array}{c}\text { Group I } \\
(n=140)\end{array}$} & \multicolumn{2}{|c|}{$\begin{array}{l}\text { Group II } \\
(n=80)\end{array}$} & \multicolumn{2}{|c|}{$\begin{array}{c}\text { Total } \\
(n=220)\end{array}$} \\
\hline & & No. & $\%$ & No. & $\%$ & No. & $\%$ \\
\hline $1-$ & Bile leak & 5 & 3.57 & 2 & 2.5 & 7 & 3.18 \\
\hline \multirow[t]{2}{*}{$2-$} & No leak & 135 & 96.43 & 78 & 97.50 & 213 & 96.82 \\
\hline & & \multicolumn{4}{|c|}{$c^{2}=0.190(d f=1) ; p=0.663$} & & \\
\hline \multicolumn{8}{|c|}{$\begin{array}{c}\text { Table 9. Between Group Comparison of Incidence of } \\
\text { Biliary Leak }\end{array}$} \\
\hline
\end{tabular}

Though, bile leak was found in higher proportion of patients of Group I (3.57\%) as compared to Group II (2.5\%), but this difference was not found to be statistically significant $(p=0.663)$.

In all the cases having biliary leak, it was peripheral in nature.

\begin{tabular}{|c|c|c|c|c|c|c|c|}
\hline \multirow{2}{*}{$\begin{array}{l}\text { Sl. } \\
\text { No. }\end{array}$} & \multirow{2}{*}{ Bile Leak } & \multicolumn{2}{|c|}{ Group I $(n=5)$} & \multicolumn{2}{|c|}{ Group II $(n=2)$} & \multicolumn{2}{|c|}{$\begin{array}{c}\text { Total } \\
(\mathrm{n}=7)\end{array}$} \\
\hline & & No. & $\%$ & No. & $\%$ & No. & $\%$ \\
\hline $1-$ & $\begin{array}{l}\text { Improper visualisation } \\
\text { leading to injury in biliary } \\
\text { tree }\end{array}$ & 4 & $80 \%$ & 1 & $50 \%$ & 5 & 71.4 \\
\hline $2-$ & Gangrenous cholecystitis & 1 & $20 \%$ & 1 & $50 \%$ & 2 & 28.6 \\
\hline
\end{tabular}

Fisher exact test: $\mathrm{p}=1.000$

In Group I out of 5 cases of bile leak 4 (80\%) were due to improper visualisation, whereas remaining 1 (20\%) was due to gangrenous cholecystitis. This difference was not significant statistically.

\begin{tabular}{|c|c|c|c|c|c|c|c|c|c|}
\hline \multirow{2}{*}{$\begin{array}{l}\text { Sl. } \\
\text { No. }\end{array}$} & \multirow{2}{*}{$\begin{array}{l}\text { Post-Operative } \\
\text { Interval }\end{array}$} & \multicolumn{3}{|c|}{ Group I } & \multicolumn{3}{|c|}{ Group II } & \multicolumn{2}{|c|}{ Significance of Difference } \\
\hline & & $\mathbf{n}$ & Mean & SD & $\mathbf{n}$ & Mean & SD & 't' & 'p' \\
\hline $1-$ & Day 1 & 120 & 27.95 & 14.07 & 80 & 45.95 & 16.35 & 8.226 & $<0.001$ \\
\hline $2-$ & Day 2 & 60 & 17.83 & 11.69 & 71 & 26.41 & 13.71 & 3.812 & $<0.001$ \\
\hline 3- & Day 3 & 8 & 23.13 & 9.23 & 26 & 17.12 & 11.06 & 1.391 & 0.174 \\
\hline 4- & Day 5 & 3 & 18.33 & 7.64 & 1 & 35.00 & . & 1.890 & 0.199 \\
\hline
\end{tabular}

Amount of drainage among patients of Group II was found to be significantly higher as compared to Group I on Day 1 p.o. ( $45.95 \pm 16.35$ vs. $27.95 \pm 14.07 \mathrm{~mL}$ ) and on Day $2(26.41 \pm 13.71$ vs. $17.83 \pm 11.69 \mathrm{~mL})$. On Day 3 p.o., mean drainage of 8 patients of Group I ( $23.13 \pm 9.23 \mathrm{~mL})$ was higher as compared to 26 patients of Group II (17.12 $\pm 11.06 \mathrm{~mL})$, but this difference was not found to be statistically significant. 
On Day 5 p.o., amount of drainage of only 1 patient of Group II was $35.00 \mathrm{~mL}$, while that of 3 patients of Group I $18.33 \pm 7.67$ $\mathrm{mL}$, but this difference was not found to be statistically significant.

On Day 7 P.O., there were only 2 cases in Group I being drained. Both had drainage $>20 \mathrm{~mL}$. In both these cases, drain was removed on Day 9 and 10. In Group II only 1 patient was left with drain on Day 7 , having drainage $>20$ mL. The patient in Group II had drainage > 10 mL till Day 18 .

\section{Management}

The management of patients was done conservatively by placing effective drain in situ. None of the cases developed peritonitis/ sepsis. The patients were kept under monitoring. None of the patients had drainage $>200 \mathrm{~mL} /$ day during the period of monitoring. Drain was removed when the amount of drainage reached to $<10 \mathrm{~mL} /$ day. The clinical course of patients in both the groups is as follows:

\section{Group I}

Out of 5 cases in this group, in two amount of drainage reached to $<10 \mathrm{~mL} /$ day on Day 4 and they were discharged. In one case, drain was removed on Day 6 and patient was discharged on Day 7. In remaining two cases, drain was removed on Day 9 and Day 10 and they were discharged on Day 11 and Day 12 respectively.

\section{Group II}

Out of two cases in this group in one case drain was removed on Day 3 and patient was discharged on Day 5, while the other patient who had a history of necrosis and ischaemia had drainage $>10 \mathrm{~mL}$ till day 18 and was subsequently discharged on Day 20.

\section{DISCUSSION}

In present study, we attempted to carry out a comparison between open cholecystectomy and laparoscopic cholecystectomy for incidence of bile leakage. For this purpose, a total of 220 patients were enrolled in the study. Of these 140 underwent laparoscopic cholecystectomy, while remaining 80 underwent open cholecystectomy procedure.

Age of patients ranged from 19 to 80 years with a mean age of $40.73 \pm 12.53$ years. Statistically, there was no significant difference in mean age of patients in two groups. There were only $8.18 \%$ cases above 60 years of age. Kiviluoto et al (1998) ${ }^{8}$ conducted their study in a study group that had $48 \%$ patients and $59 \%$ patients aged $>60$ years in open and laparoscopic cholecystectomy groups respectively.

Pessaux et al $(2001)^{9}$ in their study had all the patients > 75 years of age. Both the studies did not report any case of biliary leak, thus showing that age is not a factor influencing the incidence of biliary leak. In present study, $75 \%$ of cases were females. In LC group proportion of females was slightly higher $(77.14 \%)$ as compared to that in OC group (71.25\%), yet this difference was not significant statistically.
The age and gender profile of patients enrolled in the present study resembled to that reported in a meta-analysis by Al-Otibi ${ }^{10}$ and Al-Junaid (2016) who reported the mean age of patients to be 46.1 years and found that $81 \%$ of their patients were women. Gallstone disease is more common in females as compared to males as reported in different epidemiological studies from India.

Haematological assessment showed a generalised increase in TLC and polymorph count and low lymphocyte count, thus indicating a possible inflammatory activity. Haematological and biochemical profile of two groups was matched. Although, some authors have reported a marked elevation in liver function tests in cholecystitis patients as a result of hepatocellular injury; however, in present study no such marked elevation was observed to be reflected at group level.

There was statistically no significant difference between two groups regarding different intraoperative findings like gall bladder wall oedema, adhesions, identification of Calot's triangle, mucocele, pyocele or necrosis/ ischaemia suggestive of gangrene. Thus, suggesting that there was no difference in intraoperative findings that could affect the incidence of bile leak.

Bile leak was observed in $5(3.7 \%)$ cases of laparoscopic cholecystectomy group as compared to $2(2.5 \%)$ cases in open cholecystectomy group. Though, the incidence of bile leak was higher in LC group as compared to that in OC group, yet this difference was not significant statistically. The incidence of bile leak in present study was higher as compared to that reported by Harris, ${ }^{7}$ who reported 1 bile leak each in 100 open and 100 laparoscopic cholecystectomies. Duca et al11 also reported a much lower incidence of bile leak in their series of 9542 laparoscopic cholecystectomy subjects. They found this incidence to be only $0.57 \%$, which is much lesser than the incidence of bile leak observed in either of two groups in the present study. The incidence of bile leak in present study was close to that reported by Arroyo et $\mathrm{al}^{4}{ }^{4}$ who reported this incidence to be $2.6 \%$ of their patients undergoing open cholecystectomy. One of the reasons for slightly higher biliary leak rate in present study could be owing to a high incidence of complications like gall bladder oedema that affected $10 \%$ of OC and $14.29 \%$ of LC group patients and adhesions which comprised $22.5 \%$ of OC and $23.57 \%$ of LC group patients. Incidence of bile leak in overseas and Indian studies has shown a tremendous variability for both laparoscopic and open cholecystectomy procedures. An overview of some of the comparative studies and their comparison with the present study is as follows:

\begin{tabular}{|c|c|c|c|c|c|}
\hline Sl. No. & Author (Year) & \multicolumn{2}{|c|}{ Laparoscopic Cholecystectomy } & \multicolumn{2}{|c|}{ Open Cholecystectomy } \\
\hline & & Total Cases & \% Incidence of Bile Leak & Total Cases & \% Incidence of Bile Leak \\
\hline \multicolumn{6}{|c|}{ Overseas Studies } \\
\hline 1 & Eldar (1997) & 146 & 1.4 & 94 & 0 \\
\hline 2 & Glavic (2001) & 94 & 0 & 115 & 0.87 \\
\hline 3 & Chau (2002) & 31 & 3.2 & 42 & 4.8 \\
\hline 4 & Catena (2013) & 72 & 1.4 & 72 & 0 \\
\hline
\end{tabular}




\begin{tabular}{|c|c|c|c|c|c|}
\hline \multicolumn{6}{|c|}{ Indian Studies } \\
\hline 1 & Kapoor et al (2013) & 300 & 2.3 & & \\
\hline 2 & Karim et al (2015) & 50 & 4 & 50 & 0 \\
\hline 3 & Sankpal et al $(2016)^{6}$ & 220 & 0 & 220 & 2.7 \\
\hline 4 & Kishore et al $(2016)^{7}$ & 146 & 4.8 & 195 & 9.2 \\
\hline 5 & Present Study (2017) & 140 & 3.57 & 80 & 2.5 \\
\hline
\end{tabular}

Table 12. Incidence of Bile Leak in Overseas and Indian Studies and their Comparison with Present Study

On evaluation of different studies, we find that in different overseas studies incidence of bile leak ranged from $0 \%$ to $3.2 \%$ for LC and from $0 \%$ to $4.8 \%$ for OC. The incidence of bile leak as observed in present study for laparoscopic (3.57\%) and open (2.5\%) lies within this range.

However, in Indian studies, a relatively higher incidence of bile leak has been reported for both laparoscopic $(0$ $4.8 \%)$ as well as open (9.2\%) cholecystectomy. The incidence of bile leak in laparoscopic cholecystectomy (3.57\%) is comparable to the incidence reported by Karim et al, whereas the incidence of bile leak in open cholecystectomy as observed in presents study $(2.5 \%)$ is comparable to that observed by Sankpal et al. ${ }^{6}$

In present study, the incidence of bile leak was slightly higher in LC group (3.57\%) as compared to that in OC group $(2.5 \%)$, though this difference was not significant statistically. Out of four overseas studies, two studies have shown the incidence to be higher in laparoscopic as compared to open surgery, whereas two others have found the incidence to be higher in open as compared to laparoscopic procedure. However, in none of these studies, the differences between two techniques were significant as observed in present study too.

Among Indian studies, Karim et al reported this incidence to be higher in LC as compared to OC, whereas Sakpal et al ${ }^{6}$ and Kishore et al ${ }^{7}$ found this incidence to be higher in OC as compared to LC. In present study, we found the incidence to be similar in both the groups, but with a slightly higher proportion in LC group.

In present study, duration of hospital stay was significantly longer in OC as compared to LC group. Shorter hospital stay remains the USP of laparoscopic cholecystectomy procedure. In different clinical studies, duration of hospital stay has been one of the most distinguishing feature between two modalities. The findings of present also endorse this characteristic feature of LC.

In present study, cause of biliary leak was assigned to be improper visualisation leading to injuries to ducts in the biliary tree in four out of five (80\%) of LC and one out of two (50\%) of OC cases. The improper visualisation was primarily owing to adhesions and difficulty in identification of Calot's triangle, and in remaining one case each in both the groups gangrenous cholecystitis was the cause behind bile leak. In all the cases, the injury was peripheral in nature. Serkan et al ${ }^{12}$ in their study described difficulty in dissection of gall bladder bed. Sahu et al $^{13}$ also described separation of all adhesions and excision of gall bladder from the gall bladder fossa of the liver bed, as the intraoperative difficulties encountered during laparoscopic cholecystectomy. In present study, we also witnessed that these problems dominated the scene for

most of the incidences of bile leak. In present study in both the groups, bile leak was associated with gangrenous cholecystitis in one case each. Gangrenous cholecystitis is a difficult situation related with additional burden of complications including bile leak. The findings of present study also showed it to be one of the prominent reasons for biliary leak.

In present study, management of the patients was done conservatively. Placing effective drain in situ. None of the cases developed peritonitis/ sepsis. The patients were kept under monitoring. None of the patients had drainage $>200$ $\mathrm{mL} /$ day during the period of monitoring. Drain was removed when the amount of drainage reached to $<10 \mathrm{~mL} /$ day. The management protocol is similar to that reported by Ahmad et al, 5 who reported radical management in only those cases where peritonitis/ infection takes place or biliary leak exceeds $>200 \mathrm{~mL} /$ day. In present study, most of the patients of biliary leak were discharged from hospital within 7 days. Only 2 patients in LC group and 1 patient in OC group was discharged after 7 days. Maximum duration of hospital stay was 20 days in a patient of OC group.

The findings in present study thus showed that incidence of bile leak in present study was comparable to that reported in different Indian studies and pattern of differences between laparoscopic and open surgery were comparable to the global literature too.

Further studies on larger sample size or meta-analysis might help to elucidate the causes, role of different management strategies and outcomes in detail.

\section{CONCLUSION}

The present study was conducted to compare the biliary leak in laparoscopic and open cholecystectomy. A total of 220 cases of cholecystectomy who attended the institution for surgical management, $140(63.64 \%)$ patients had undergone laparoscopic cholecystectomy (LC) and rest 80 had undergone open cholecystectomy (OC). From our study, it can be concluded that the incidence of bile leak in laparoscopic and open cholecystectomy was comparable and in agreement with the reported incidence in literature. However, cause of bile leak was primarily visualisation in both the groups; however, necrosis and ischaemia suggestive of gangrenous cholecystitis also posed risk of bile leak. In the present study, all the cases had peripheral leak that was managed successfully by conservative management. Endoscopic sphincterotomy and ERCP are mode of management for patients who cannot be managed conservatively, which in the present study had not been used.

\section{REFERENCES}

[1] NIH - National Institute of Diabetes and Digestive and Kidney Diseases. Cholecystectomy.

[2] Holzheimer RG, Mannick JA. Surgical treatment: evidence-based and problem-oriented. Munich: Zuckschwerdt 2001.

[3] Smith JF, Boysen D, Tschirhart J, et al. Comparison of laparoscopic cholecystectomy versus elective open cholecystectomy. J Laparoendosc Surg 1992;2(6): 311-7. 
[4] Arroyo K, Bonadies J, Ciardiello K. Bile leak in open cholecystectomy: related to gangrenous cholecystitis? Conn Med 2010;74(6):329-31.

[5] Ahmad F, Saunders RN, Lloyd GM, et al. An algorithm for the management of bile leak following laparoscopic cholecystectomy. Annals of The Royal College of Surgeons of England 2007;89(1):51-6.

[6] Sankpal J, Jadhav S, Tayade M, et al. Clinical study of complications of laparoscopic cholecystectomy and open cholecystectomy. JMSCR 2016;4(11):13745-51.

[7] Harris BC. Retrospective comparison of outcome of 100 consecutive open cholecystectomies and 100 consecutive laparoscopic cholecystectomies. South Med J 1993;86(9):993-6.

[8] Kiviluoto T, Sirén J, Luukkonen P, et al. Randomised trial of laparoscopic versus open cholecystectomy for acute and gangrenous cholecystitis. The Lancet 1998;351(9099):321-5.

[9] Pessaux P, Regenet N, Tuech JJ, et al. Laparoscopic versus open cholecystectomy: a prospective comparative study in the elderly with acute cholecystitis. Surg Laparosc Endosc Percutan Tech 2001;11(4):252-5.
[10] Al-Otibi RF, Al-Junied NJA. A comparison of open cholecystectomy surgical method with the laparoscopic one. International Journal of Healthcare Sciences 2016;3(2):217-22.

[11] Duca S, Bãlã O, Al-Hajjar N, et al. Laparoscopic cholecystectomy: incidents and complications. A retrospective analysis of 9542 consecutive laparoscopic operations. HPB (Oxford): The Official Journal of the International Hepato Pancreato Biliary Association 2003;5(3):152-8.

[12] Serkan S, Suleyman S, Egemen C, et al. Evaluation of potential intraoperative technical difficulties with ultrasonography before laparoscopic cholecystectomy. European Journal of Surgical Sciences 2012;3(1):1521.

[13] Sahu SK, Agrawal A, Sachan PK. Intraoperative difficulties in laparoscopic cholecystectomy. Jurnalulde Chirurgie (Iaşi) 2013;9(2):149-55. DOI: 10.7438/1584-9341-9-2-5. 